\title{
INFLUÊNCIA DA TEMPERATURA FINAL DE CARBONIZAÇÃO NAS CARACTERÍSTICAS FÍSICAS E QUÍMICAS DO CARVÃO VEGETAL DE JATOBÁ (Himenea courbaril L.)
}

\author{
INFLUENCE OF FINAL CARBONIZATION TEMPERATURE IN \\ THE PHYSICAL AND CHEMICAL CHARACTERISTICS \\ OF THE JATOBÁ(Himenea courbaril L.) CHARCOAL
}

\author{
Paulo Fernando TRUGILHO ${ }^{1}$ \\ Dimas Agostinho da SILVA ${ }^{2}$
}

\begin{abstract}
RESUMO
O objetivo deste trabalho foi verificar a influência da temperatura final de carbonização sobre algumas das principais características físicas e químicas desejáveis no carvão vegetal de jatobá (Himenea courbaril L.) e o comportamento dos materiais cerne e alburno frente ao processo de carbonização. Verificar, também, a relação entre a composição química do carvão e o seu poder calorífico superior. Foram analisadas algumas das características físicas e químicas do carvão vegetal. Os resultados demonstraram haver diferenças entre o carvão vegetal do cerne e alburno provocadas, provavelmente, pela diferente composição química e anatômica dos materiais avaliados. A densidade relativa aparente passa por um ponto de mínimo em $660^{\circ} \mathrm{C}$, para os dois materiais usados. O rendimento em carbono não variou significativamente com o aumento da temperatura final de carbonização. O teor de carbono fixo, de cinzas e o poder calorífico superior do carvão vegetal aumentaram com o aumento da temperatura de carbonização. Comportamento contrário ocorreu para teor de materiais voláteis. Existe uma relação funcional positiva entre o poder calorífico superior do carvão vegetal e o teor de carbono fixo e o teor de cinzas, e uma relação funcional negativa com o teor de materiais voláteis.
\end{abstract}

Palavras-chave: carvão vegetal, temperatura, características físicas e químicas, cerne e alburno, jatobá.

\begin{abstract}
The purpose of this study was to verify the relationship between the pyrolisis and physical and chemical characteristics of the jatobá (Himenea courbaril L.) charcoal. It was also studied the behavior of the heartwood and sapwood with respect to the carbonization process and the effects of its chemical composition to the heat of combustion of the fuelwood. In addition, some physical-chemical characteristics of the wood charcoal were analyzed. The results suggest that the difference between the heartwood and sapwood charcoal is caused by differences anatomical structure and chemical composition of the materials. It was also determined that the charcoal specific gravity pass over a minimum point at $660^{\circ} \mathrm{C}$ for both heartwood and sapwood. It was not observed any change in the fixed yield carbon of charcoal obtained from heartwood and sapwood with the increase of the final carbonization temperature. Finally, it was determined a positive relationship between the heat of combustion of the wood charcoal with its fixed carbon and ash contents and negative relationship with the volatile material contents.

Key words: Charcoal, temperature, physical and chemical characteristics, heartwood and sapwood, jatobá.
\end{abstract}

\footnotetext{
1 Engenheiro Florestal, Doutor, Universidade Federal de Lavras, Departamento de Ciências Florestais, Professor, CEP 37200-00, Lavras, MG. झ Autor para correspondência.

2 Engenheiro Florestal, Doutor, Universidade Federal do Paraná, Departamento de Engenharia e Tecnologia Florestal, Professor, Curitiba, PR. E-mail: dimass@floresta.ufpr.br
} 


\section{INTRODUÇÃO}

A madeira, quando submetida a ação do calor, em temperaturas relativamente elevadas, sofre um processo de transformação no qual todos os seus componentes são exaustivamente modificados (Gomes e Oliveira, 1980) [6].

Carbonização é um processo de decomposição térmica que a madeira sofre, na ausência ou na presença de quantidades controladas de oxigênio, gerando um resíduo sólido, chamado carvão vegetal (Wenzl, 1970) [19]. O processo, além do carvão, gera vapor d'água, líquidos orgânicos e gases não-condensáveis, ficando o carvão vegetal como resíduo sólido (Gomes e Oliveira, 1980) [6].

A carbonização da madeira envolve, portanto, fenômenos demasiadamente complexos que possibilitam a geração de um elevado número de compostos. Ela pode ser dividida em quatro etapas conforme a temperatura (Medeiros e Resende, 1983) [7]; (Oliveira et. al., 1982) [10]: a) abaixo de $200^{\circ} \mathrm{C}$ - praticamente só ocorre a secagem da madeira; b) de 200 a $280^{\circ} \mathrm{C}$ - predominância de reações endotérmicas, com liberação de ácido acético, metanol, água, $\mathrm{CO}_{2}$ e outros; c) de 280 a $500^{\circ} \mathrm{C}$ - predominância de reações exotérmicas, que levam à liberação de gases combustíveis $\left(\mathrm{CO}, \mathrm{CH}_{4} \mathrm{e}\right.$ outros) e alcatrões; e d) acima de $500^{\circ} \mathrm{C}$ - liberação de pequenas quantidades de voláteis, em especial $\mathrm{H}_{2}$.

Essas etapas podem ocorrer de modo simultâneo durante a carbonização. Cada faixa de temperatura é responsável por um tipo de produto, com características próprias. A temperatura final de carbonização é, portanto, uma das variáveis responsáveis, juntamente com a espécie, pela qualidade final do carvão vegetal. Ela desempenha um papel fundamental nas diversas reações durante o processo de carbonização, levando à geração de produtos com características físicas e químicas diferentes.

A madeira é um material altamente desuniforme. Variações entre e dentro das espécies são atribuídas, principalmente, a fatores genéticos e ambientais. Diferenças significativas ocorrem entre cerne e alburno, madeira de início e madeira de fim de estação de crescimento, e em escala microscópica, observa-se diferença até mesmo entre células individuais. A madeira de cerne contém mais compostos fenólicos (taninos) e ácidos e menos amido que a madeira de alburno. O cerne possui um tecido mais compacto e menos permeável (Burger e Richter, 1991) [5]. Essas diferenças nas composições químicas, físicas e morfológicas podem levar a produtos finais com características completamente distintas.

As propriedades do carvão vegetal estão diretamente relacionadas às características físicas, químicas e anatômicas da madeira utilizada na sua produção. Entre todas as características físicas da madeira, a densidade básica é a que tem maior influência sobre a qualidade do carvão e entre as características químicas o destaque é para o teor de lignina.
Os objetivos do presente trabalho foram: a) verificar a influência da temperatura final de carbonização sobre algumas das principais características físicas e químicas desejáveis no carvão vegetal; b) avaliar o comportamento dos materiais cerne e alburno frente ao processo de carbonização; e c) verificar a relação funcional existente entre a composição química do carvão e o seu poder calorífico superior.

\section{METODOLOGIA}

A madeira utilizada neste estudo foi de jatobá (Himenea coubaril L.). A escolha do jatobá está relacionada com facilidade na separação de amostras distintas e representativas dos materiais cerne e alburno, os quais são bem visíveis nesta madeira. As amostras retiradas, tanto para cerne quanto alburno, tinham dimensões de $2 \times 2 \times 3 \mathrm{~cm}$.

As carbonizações foram realizadas em um forno elétrico (mufla) adaptado com cápsula em vidro para pirólise, condensador resfriado à água e frasco coletor (kitasato) de materiais voláteis condensáveis. As amostras eram previamente secas em estufa a $105 \pm 3^{\circ} \mathrm{C}$ e depois submetidas, na mufla, às temperaturas finais de $300,400,500$, $600,700,800$ e $900^{\circ} \mathrm{C}$, com uma taxa de aquecimento de $50^{\circ} \mathrm{C}$ a cada $25 \mathrm{~min}$, partindo-se sempre de uma temperatura inicial de $100^{\circ} \mathrm{C}$. Em cada ensaio usou-se, aproximadamente, $150 \mathrm{~g}$ de material. $\mathrm{O}$ forno elétrico era desligado imediatamente após atingida a temperatura final de carbonização. As amostras de cerne e alburno foram marcadas por um pirógrafo e submetidas à carbonização.

Após as carbonizações foram determinados:

a) rendimento gravimétrico da carbonização, calculado pela expressão:

$$
\mathrm{RGC}=(\mathrm{PCS} / \mathrm{PMS}) \times 100
$$

em que, RGC = rendimento gravimétrico da carbonização (\%), PCS = peso do carvão seco (g) e PMS = peso da madeira seca $(\mathrm{g})$, tanto para o cerne quanto para o alburno; b) rendimento em carbono fixo, determinado pela equação:

$$
\mathrm{RCF}=(\mathrm{RGC} \times \mathrm{TCF}) / 100
$$

onde, $\mathrm{RCF}=$ rendimento em carbono fixo (\%), $\mathrm{RGC}=$ rendimento gravimétrico da carbonização (\%) e TCF = teor de carbono fixo (\%); c) composição química imediata, determinando-se os teores de materiais voláteis, de cinzas e de carbono fixo (Norma NBR 8112 da ABNT); d) densidade relativa aparente, determinada por um equipamento de imagens chamado MICRO VIDEOMAT; que foi utilizado para medida das dimensões das peças, para cálculos do volume (foram usadas cinco amostras para cerne e alburno); e e) poder calorífico superior, calculado conforme procedimento descrito na Norma NBR 8633 da ABNT.

O delineamento experimental usado foi o inteiramente casualizado, com sete tratamentos 
(temperaturas) e quatro repetições, sendo ajustado um modelo de regressão para cada característica avaliada.

\section{RESULTADOS E DISCUSSÃO}

Os resultados das características avaliadas no carvão vegetal do material cerne e alburno estão apresentados na Quadro 1.

Para as temperaturas de 300 e $400^{\circ} \mathrm{C}$, tanto no cerne quanto no alburno, o tempo de exposição não foi suficiente para promover a completa decomposição térmica do material o que, provavelmente, foi responsável pela obtenção de valores muito discrepantes em relação as outras faixas de temperatura. A decomposição depende da quantidade de energia disponível e, portanto, do binômio tempo-temperatura. De acordo com Almeida e Resende (1982) [1], o carvão vegetal pode ser considerado como tal a partir de temperaturas acima de $300^{\circ} \mathrm{C}$. No presente estudo, provavelmente, o tempo de exposição empregado não foi suficiente para permitir a completa transferência de calor para os materiais em estudo. Especificamente para a temperatura de $300^{\circ} \mathrm{C}$ os dois materiais utilizados sofreram pequena decomposição, podendo ser caracterizados apenas como madeira torrificada.

QUADRO 1 - Rendimentos e características físicas e químicas do carvão vegetal do cerne e do alburno, Curitiba, PR, 1995/99 ${ }^{1}$

\begin{tabular}{|c|c|c|c|c|c|c|c|c|c|c|c|c|c|c|}
\hline \multirow{2}{*}{$\begin{array}{c}\text { TEMP. } \\
\text { FINAL }\left({ }^{\circ} \mathrm{C}\right)\end{array}$} & \multicolumn{7}{|c|}{ CERNE } & \multicolumn{7}{|c|}{ ALBURNO } \\
\hline & DRA & RGC & RCF & PCS & TMV & TCF & TCZ & DRA & RGC & RCF & PCS & TMV & TCF & TCZ \\
\hline 300 & 0,928 & 92,94 & 20,07 & 4833,55 & 78,01 & 21,59 & 0,403 & 0,718 & 94,35 & 16,47 & 4559,32 & 82,27 & 17,46 & 0,278 \\
\hline 500 & 0,714 & 44,00 & 29,72 & 5496,40 & 31,36 & 67,55 & 1,090 & 0,528 & 35,56 & 23,94 & 6012,20 & 31,29 & 67,32 & 1,390 \\
\hline 600 & 0,695 & 38,62 & 29,64 & 7265,14 & 23,24 & 75,72 & 1,175 & 0,509 & 31,64 & 23,65 & 7362,62 & 23,80 & 74,76 & 1,440 \\
\hline 800 & 0,714 & 31,98 & 29,14 & 7830,40 & 7,32 & 91,11 & 1,570 & 0,536 & 26,88 & 24,25 & 7635,44 & 7,98 & 90,25 & 1,770 \\
\hline 900 & 0,741 & 31,24 & 28,71 & 8175,08 & 6,74 & 92,22 & 1,500 & 0,557 & 26,04 & 24,24 & 7896,72 & 6,26 & 93,09 & 1,403 \\
\hline
\end{tabular}

As diferenças mais marcantes entre os dois materiais usados são quanto às características densidade relativa aparente, rendimento gravimétrico da carbonização e rendimento em carbono fixo, todas elas sempre superiores no material cerne. Esse fato é plenamente aceitável, pois a densidade do material cerne é maior que a do material alburno, devido a variações morfológicas, como maior espessura da parede celular e, também, devido a diferenças químicas. Esses resultados sugerem que o cerne tem maior teor de lignina que o alburno, pois segundo Trugilho et al. (1997) [16], a lignina é o principal componente químico estrutural da madeira responsável pela produção do carvão vegetal. Trugilho et al.(1997) (16) concluíram que as madeiras de elevado teor de lignina e com alta densidade são mais indicadas para produção de carvão vegetal.

Segundo Sarkanen e Ludwig (1971) [12] a lignina é o componente da madeira mais estável termicamente, quando comparada com a celulose, com as hemiceluloses e com a própria madeira. Esse fato está relacionado com a estrutura química complexa e com os tipos de ligações presentes na lignina. Quando se carboniza uma madeira rica em lignina, obtêm-se um elevado rendimento gravimétrico e carvão com alto teor de carbono. Esse fato está relacionado com a maior resistência à decomposição térmica que a lignina possui, em relação aos demais constituintes estruturais da madeira (Andrade, 1993) [2].

Além disso, segundo Burger e Richter (1991) [5] o cerne é formado por um tecido mais compacto que o alburno, o que também pode ter contribuído para a maior resistência oferecida por este material frente a decomposição térmica.

O Quadro 2 apresenta as equações ajustadas para as características avaliadas no material cerne e alburno. O Quadro 3 apresenta os coeficientes de correlação linear simples entre as características avaliadas no material cerne e no material alburno.

A regressão somente foi não significativa para a característica rendimento em carbono fixo. Esse comportamento indica que a resposta ajustada foi a mesma, independentemente da temperatura usada, isto é, não existe relação funcional significativa entre rendimento em carbono fixo e temperatura final de carbonização, tanto para cerne quanto para alburno. Isso se deve ao fato do rendimento em carbono fixo ser formado por uma combinação entre o rendimento gravimétrico em carvão e o teor de carbono fixo. Assim, a redução do rendimento gravimétrico, em temperatura mais elevadas, é prontamente contrabalanceada com o aumento o teor de carbono, não alterando o valor do rendimento em carbono.

A equação ajustada para a densidade relativa aparente, por ser da forma polinomial quadrática, passa por ponto de mínimo, tanto para cerne quanto para alburno. Por meio das derivadas parciais pode- 
QUADRO 2 - Equações ajustadas para as características avaliadas no cerne e no alburno, Curitiba, PR, $1995 / 99$

\begin{tabular}{|c|c|c|c|c|}
\hline \multirow{2}{*}{ Característica } & \multicolumn{4}{|c|}{ EQUAÇÕES AJUSTADAS } \\
\hline & CERNE & $\mathrm{R}^{2}$ & ALBURNO & $\mathrm{R}^{2}$ \\
\hline DRA & $\hat{Y}_{i}=1,4176-0,002248 X_{i}+0,000001682 X_{i}^{2}$ & $0,88^{*}$ & $\hat{Y}_{i}=1,1511-0,002014 X_{i}+0,000001526 X_{i}^{2}$ & $0,84^{*}$ \\
\hline RGC & $\hat{Y}_{i}=96,6407-0,08358 X_{i}$ & $0,69^{*}$ & $\hat{Y}_{i}=92,7514-0,08667 X_{i}$ & $0,59^{*}$ \\
\hline RCF & $\hat{Y}_{i}=23,2464+0,008354 X_{i}$ & $0,24 \mathrm{~ns}$ & $\hat{Y}_{i}=18,3950+0,007882 X_{i}$ & $0,33 n s$ \\
\hline PCS & $\hat{Y}_{i}=2851,60+6,24382 X_{i}$ & $0,92^{*}$ & $\hat{Y}_{i}=3181,19+5,71871 X_{i}$ & $0,90^{*}$ \\
\hline TMV & $\hat{Y}_{i}=92,3914-0,10654 X_{i}$ & $0,84^{*}$ & $\hat{Y}_{i}=95,4471-0,11044 X_{i}$ & $0,82^{*}$ \\
\hline TCF & $\hat{Y}_{i}=7,2736+0,105318 X_{i}$ & $0,84^{*}$ & $\hat{Y}_{i}=3,8993+0,109518 X_{i}$ & $0,82^{*}$ \\
\hline TCZ & $\hat{Y}_{i}=0,1266+0,001708 X_{i}$ & $0,87^{*}$ & $\hat{Y}_{i}=0,2834+0,001716 X_{i}$ & $0,56 n s$ \\
\hline
\end{tabular}

QUADRO 3 - Coeficientes de correlação simples entre as características avaliadas em cerne e alburno, Curitiba, PR, 1995/99

\begin{tabular}{|c|c|c|c|c|c|c|c|}
\hline & DRA & RGC & RCF & PCS & TMV & TCF & TCZ \\
\hline DRA & $\begin{array}{l}C \\
A\end{array}$ & $\begin{array}{c}0,9249^{*} \\
\left(0,9313^{*}\right)\end{array}$ & $\begin{array}{c}-0,9623^{*} \\
\left(-0,9418^{*}\right)\end{array}$ & $\begin{array}{c}-0,5760^{\text {ns }} \\
\left(-0,6701^{*}\right)\end{array}$ & $\begin{array}{c}0,8560^{*} \\
\left(0,8322^{*}\right)\end{array}$ & $\begin{array}{c}-0,8548^{*} \\
\left(-0,8258^{*}\right)\end{array}$ & $\begin{array}{r}-0,8078^{*} \\
\left(-0,9230^{*}\right)\end{array}$ \\
\hline RGC & & C & $\begin{array}{c}-0,8859^{*} \\
\left(-0,9461^{*}\right)\end{array}$ & $\begin{array}{c}-0,7913^{*} \\
\left(-0,8400^{\star}\right)\end{array}$ & $\begin{array}{c}0,9319^{*} \\
\left(0,9670^{*}\right)\end{array}$ & $\begin{array}{c}-0,9818^{*} \\
\left(-0,9649^{\star}\right.\end{array}$ & $\begin{array}{c}-0,9612^{*} \\
\left(-0,9639^{\star}\right.\end{array}$ \\
\hline RCF & & & $\begin{array}{l}\text { C } \\
\text { A }\end{array}$ & $\begin{array}{c}0,4440^{\text {ns }} \\
\left(0,6380^{\text {ns }}\right)\end{array}$ & $\begin{array}{c}-0,7933^{*} \\
\left(-0,8563^{*}\right)\end{array}$ & $\begin{array}{c}0,7923^{*} \\
\left(0,8528^{*}\right)\end{array}$ & $\begin{array}{c}0,7503^{*} \\
\left(0,8950^{*}\right)\end{array}$ \\
\hline PCS & & & & C & $\begin{array}{c}-0,8781^{*} \\
\left(-0,9321^{*}\right)\end{array}$ & $\begin{array}{c}0,8793^{*} \\
\left(0,9338^{*}\right)\end{array}$ & $\begin{array}{c}0,8820^{*} \\
\left(0,8331^{*}\right)\end{array}$ \\
\hline TMV & & & & & C & $\begin{array}{c}-1,000^{*} \\
\left(-0,9999^{*}\right)\end{array}$ & $\begin{array}{c}-0,9926^{*} \\
\left(-0,9488^{*}\right.\end{array}$ \\
\hline TCF & & & & & & $\begin{array}{l}\mathrm{C} \\
\mathrm{A}\end{array}$ & $\begin{array}{c}0,9923^{*} \\
\left(0,9437^{\star}\right)\end{array}$ \\
\hline TCZ & & & & & & & $\begin{array}{l}\mathrm{C} \\
\mathrm{A}\end{array}$ \\
\hline
\end{tabular}

DRA = Densidade Relativa Aparente $\quad$ RGC = Rendimento Gravimétrico em Carvão RCF = Rendimento em Carbono Rixo

PCS $=$ Poder Calorífico Superior TMV $=$ Teor de Materiais Voláteis $\quad$ TCF $=$ Teor de Carbono Fixo

TCZ $=$ Teor de Cinzas $\quad X=$ Temperatura Final de Carbonização $\quad C=$ Cerne $A=$ Alburno

* Significativo, pelo teste $\mathrm{F}$, a $5 \%$ de probabilidade.

ns Não significativo.

se concluir que a função passa por ponto de mínimo, independentemente do material usado. Para o cerne, o ponto mínimo foi de $667^{\circ} \mathrm{C}$, o que correspondeu a uma densidade de $0,667 \mathrm{~g} \cdot \mathrm{cm}^{-3}$. Para o alburno, o ponto de mínimo foi de $660^{\circ} \mathrm{C}$, o que correspondeu a uma densidade de $0,486 \mathrm{~g} . \mathrm{cm}^{-3}$.

Pelo Quadro 3 nota-se que os coeficientes de correlação simples possuem sempre o mesmo sinal e com magnitudes muito próximas, para os dois materiais usados. Somente o rendimento em carbono fixo originou coeficiente não-significativo com o poder calorífico superior, indicando uma falta de relacionamento linear entre as duas variáveis, tanto para o cerne quanto para o alburno. Para o cerne, o coeficiente de correlação linear entre a densidade relativa aparente e o poder calorífico superior foi não significativo.

No Quadro 4 encontram-se as equações ajustadas entre o poder calorífico superior $\mathrm{e}$ as características químicas do carvão, para o cerne e o alburno. Pode-se observar que o modelo linear simples é mais adequado que o modelo linear múltiplo, pois a inclusão de variáveis provoca uma melhoria muito pequena no ajuste. Assim, tanto o teor de carbono fixo quanto o teor de materiais voláteis podem ser usados, separadamente, na estimativa do poder calorífico superior. Stimely e Blankenhorn (1985) [15] mencionam a existência de relação positiva entre o poder calorífico do carvão e o seu conteúdo de carbono.

A Figura 1 mostra o comportamento da densidade relativa aparente frente a temperatura final de carbonização. Observa-se que, tanto para cerne quanto para alburno, as funções passam por um ponto de mínimo, já mencionado anteriormente.

As densidades relativas aparentes do cerne e do alburno decrescem até, aproximadamente, $660^{\circ} \mathrm{C}$ e voltam a subir com o aumento da temperatura final. Esse fato está de acordo com Blanknhorn (1978) [3], que encontrou resultado semelhante em Prunus serotina e Oliveira e Almeida (1980) [9], com Eucalyptus grandis. Esse fato ocorre devido a perda de massa causada pela liberação dos materiais voláteis. De 300 a $500^{\circ} \mathrm{C}$ a perda de massa é bem maior que a redução nas dimensões do carvão, acarretando, assim, um decréscimo na sua densidade aparente. A partir de $600^{\circ} \mathrm{C}$, a perda de massa passa a ser menor que a contração nas 
QUADRO 4 - Equações ajustadas para o poder calorífico superior $\left(\hat{Y}_{i}\right)$ no cerne e no alburno, Curitiba, PR, 1995/99

\begin{tabular}{|c|c|c|c|}
\hline \multicolumn{4}{|c|}{ EQUAÇÕES AJUSTADAS } \\
\hline CERNE & $\mathrm{R}^{2}$ & ALBURNO & $\mathrm{R}^{2}$ \\
\hline$\hat{Y}_{i}=-198727,0+2019,45 X_{1 i}+2016,12 X_{2 i}+5008,98 X_{3 i}$ & $0,83^{* *}$ & $\hat{Y}_{i}=589152,0-5862,12 X_{1 i}-5606,66 X_{2 i}-16123,4 X_{3 i}$ & $0,98^{* *}$ \\
\hline$\hat{Y}_{i}=-140837,0+1441,54 X_{1 i}+1509,90 X_{2 i}$ & $0,80^{*}$ & $\hat{Y}_{i}=-27575,0+310,261 X_{1 i}+361,044 X_{2 i}$ & $0,88^{*}$ \\
\hline$\hat{Y}_{i}=7992,19-48,9741 X_{1 i}$ & $0,77^{*}$ & $\hat{Y}_{i}=7949,61-45,8166 X_{1 i}$ & $0,87^{*}$ \\
\hline$\hat{Y}_{i}=3097,31+49,6788 X_{2 i}$ & $0,77^{*}$ & $\hat{Y}_{i}=3373,02+46,5364 X_{2 i}$ & $0,87^{*}$ \\
\hline$\hat{Y}_{i}=2999,60+3125,85 X_{3 i}$ & $0,78^{*}$ & $\hat{Y}_{i}=3742,41+2185,40 X_{3 i}$ & $0,69^{*}$ \\
\hline
\end{tabular}
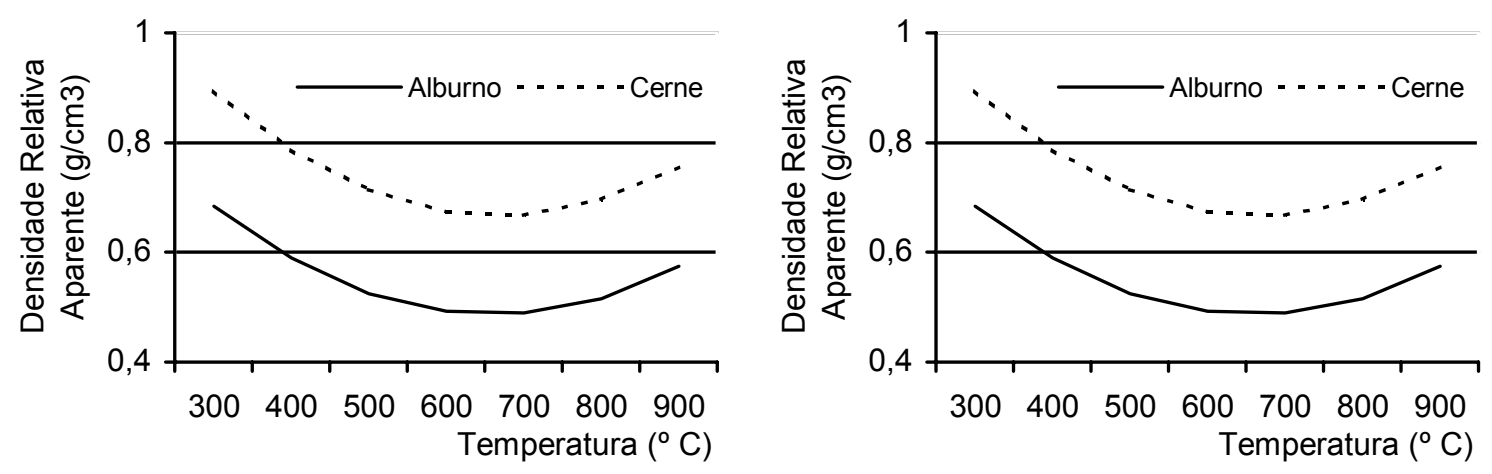

FIGURA 1 - Densidade relativa aparente e rendimento gravimétrico da carbonização em função da temperatura final para alburno e cerne, Curitiba, PR, 1995,99

dimensões do carvão, o que resulta no aumento da sua densidade aparente. Essa contração pode estar relacionada com um possível rearranjo estrutural do carbono residual.

Pelo gráfico da Figura 1 pode-se verificar que existe um decréscimo mais acentuado do rendimento gravimétrico em temperaturas mais baixas e à medida em que se aumenta a temperatura final de carbonização, parece haver tendência de estabilização, tanto no cerne quanto no alburno. Esses resultados estão plenamente de acordo com Valente et. al. (1985) [18], Gomes e Oliveira (1980) [6] e Oliveira et al. (1982) [10, 11], que trabalharam com Eucalyptus grandis W. Hill exMaiden.

As Figuras 2 e 3 mostram a variação das características químicas e poder calorífico superior do carvão com a temperatura final de carbonização, tanto para cerne quanto para alburno.

Pela Figura 2 pode-se observar que o teor de materiais voláteis diminui sensivelmente com o aumento da temperatura final de carbonização. Esse resultado está de acordo Silva e Brito (1989) [14], Valente et. al. (1985) [18] e Wenzl (1970) [19]. Parece haver tendência de estabilização em temperaturas mais elevadas, independente do material usado. Em temperaturas mais elevadas somente pequenas quantidades de $\mathrm{H}_{2}$ são liberadas do carvão, daí haver tendência na estabilização.

O comportamento inverso ocorre com o teor de carbono fixo, como é mostrado,também na Figura 2. Esse fato está de acordo com vários autores, tais como Silva (1988) [13], Wenzl (1970) [19], Uhart (1976) [17], dentre outros. Aqui, também, parece ocorrer tendência de estabilização em temperaturas mais elevadas, para cerne e alburno. A eliminação dos materiais voláteis no carvão provoca um aumento natural no seu teor de carbono fixo. Normalmente, quando se carboniza uma madeira rica em lignina, obtém-se um elevado rendimento gravimétrico e o carvão apresenta um alto teor de carbono (Brito e Barrichelo, 1977) [4].

A Figura 3 mostra o comportamento dos elementos minerais, cinzas, com a temperatura carbonização que aumenta até $800^{\circ} \mathrm{C}$ e em $900^{\circ} \mathrm{C}$ houve um decréscimo, para os dois materiais usados.

Esse decréscimo pode ser explicado pelo fato de haver ocorrido a vaporização (ignição) de algum componente mineral nessa temperatura. O aumento no teor de cinzas, com o aumento da temperatura, era esperado, uma vez que esses componentes permanecem intactos, isto é, são transferidos completamente da madeira para o carvão vegetal, isso ocorre normalmente em temperaturas mais baixas que $900^{\circ} \mathrm{C}$.

$\mathrm{Na}$ Figura 3 pode-se, ainda, observar um aumento do poder calorífico com o aumento da temperatura final de carbonização. Este comportamento se deve ao fato do teor de carbono fixo também aumentar com o aumento da temperatura. O teor de carbono fixo é, juntamente com o teor de materiais voláteis, a principal característica que determina o poder calorífico superior do carvão vegetal. Esse resultado está de 
acordo com os encontrados por Mendes et. al. (1982) [8]. Existe, dessa forma, um balanço entre o teor de carbono fixo e o teor de materiais voláteis, que determinam o seu poder calorífico superior.

As Figuras 4 e 5 mostram a relação entre o poder calorífico superior do carvão e as características químicas do carvão, para cerne e alburno, respectivamente. Nessas figuras observase que o poder calorífico superior é diretamente proporcional ao teor de carbono fixo e inversamente proporcional ao teor de materiais voláteis, independentemente do material usado. Quanto ao aumento do poder calorífico superior com a elevação do teor de cinzas, isto foi provocado por um efeito indireto. Normalmente o poder calorífico e a qualidade do carvão reduzem com o aumento do teor de cinzas.
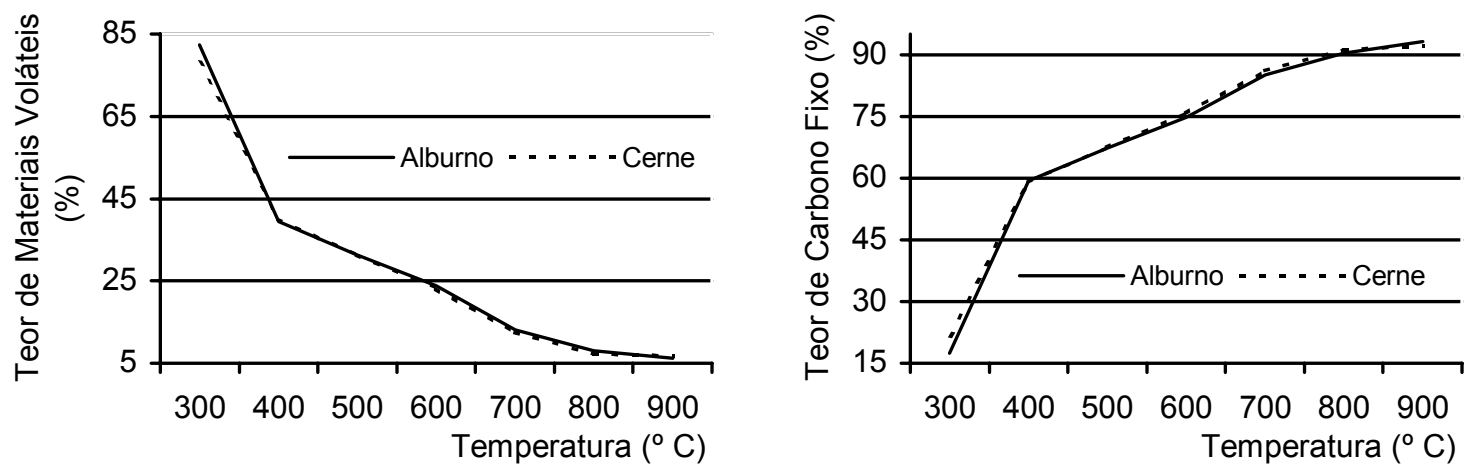

FIGURA 2 - Teor de materiais voláteis e teor de carbono fixo em função da temperatura final para alburno e cerne, Curitiba, PR, 1995,99
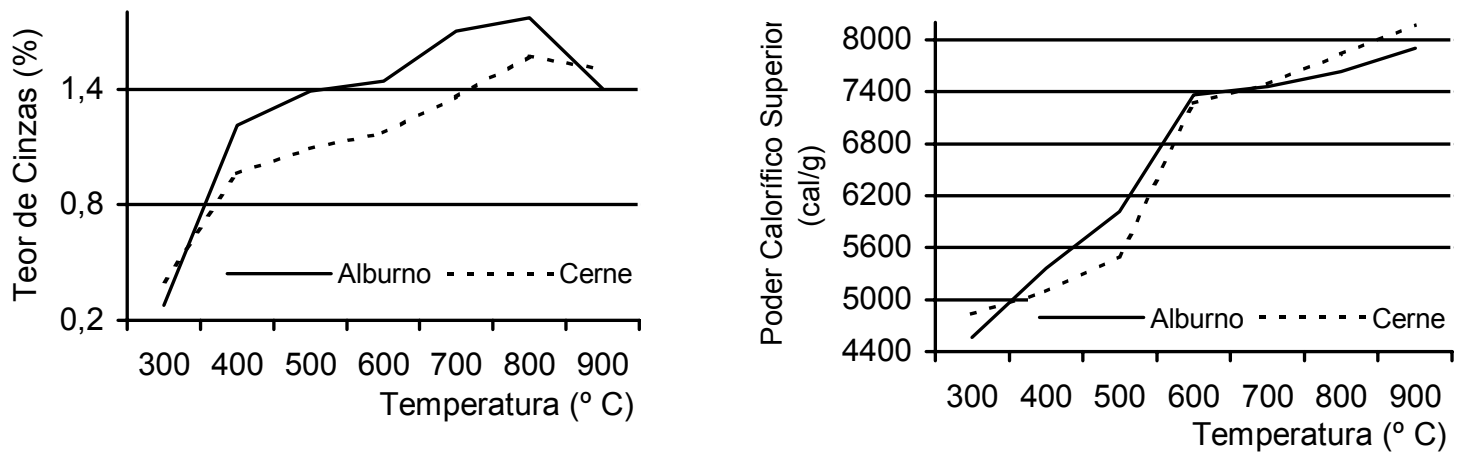

FIGURA 3 - Teor de cinzas e poder calorífico superior em função da temperatura final de carbonização para alburno e cerne, Curitiba, PR, 1995,99
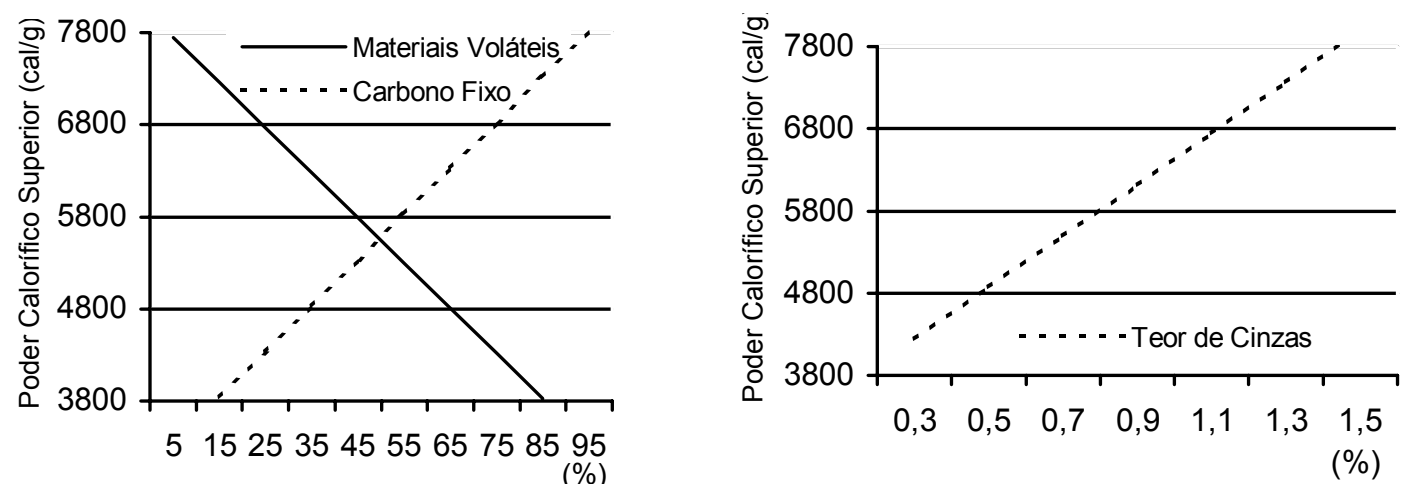

FIGURA 4 - Relação funcional entre o poder calorífico superior e o teor de materiais voláteis, o teor de carbono fixo e o teor de cinzas para o cerne, Curitiba, PR, 1995,99 


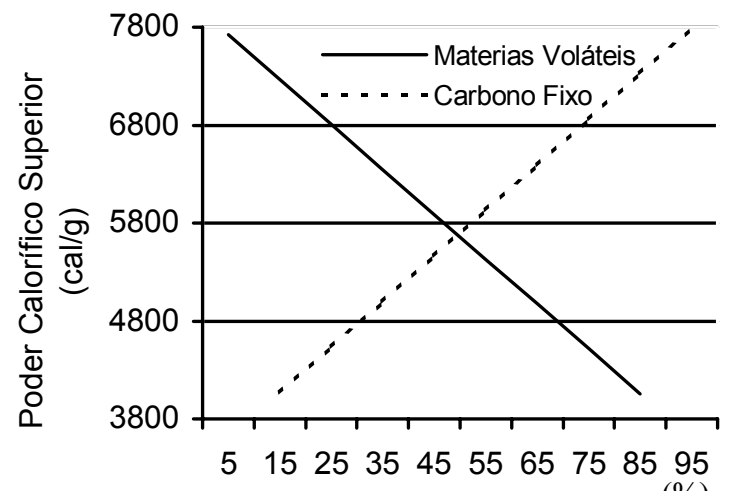

$(\%)$

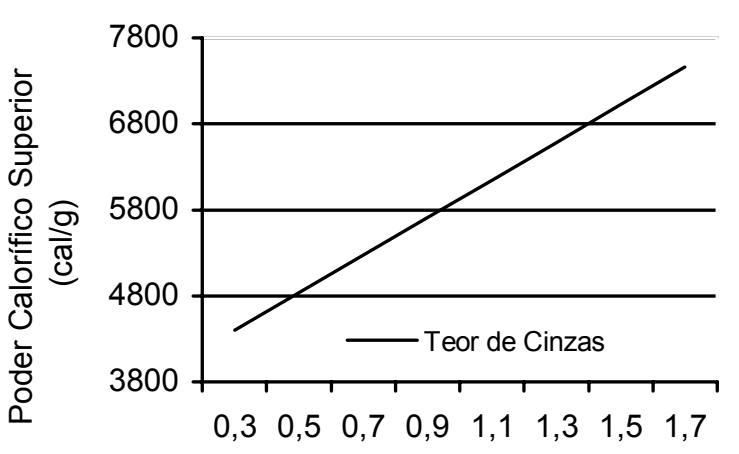

(\%)

FIGURA 5 - Relação funcional entre o poder calorífico superior e o teor de materiais voláteis, o teor de carbono fixo e o teor de cinzas para o alburno, Curitiba, PR, 1995,99

\section{CONCLUSÕES}

1) A temperatura final de carbonização é determinante na qualidade do carvão vegetal obtido, tanto do cerne quanto do alburno.

2) O cerne produz mais carvão que o alburno.

3) Os materiais de cerne e alburno apresentam comportamentos distintos com a temperatura final.

4) O rendimento em carbono fixo não é influenciado significativamente pela temperatura final de carbonização.

5) A densidade relativa aparente aumenta depois de passar pelo ponto do mínimo em aproximadamente $660^{\circ} \mathrm{C}$.

6) A densidade relativa aparente é maior no cerne.

7) $O$ rendimento gravimétrico da carbonização diminui com o aumento da temperatura final de carbonização com tendência de estabilização nas temperaturas mais elevadas.

8) O teor de carbono fixo, de cinzas e poder calorífico superior aumentam com o aumento da temperatura final de carbonização.

9) O teor de materiais voláteis diminui com o aumento da temperatura final de carbonização.

10) O teor de cinzas presente no cerne é maior que o encontrado no alburno.

11) $O$ poder calorífico superior aumenta com o teor de carbono fixo e diminui com o teor de materiais voláteis.

\section{REFERÊNCIAS}

[1] ALMEIDA, M. R.; RESENDE, M. E. A. O processo de carbonização contínua da madeira. In: PENEDO, W. R. (Ed.) Produção e utilização de carvão vegetal. Belo Horizonte: CETEC, 1982. p. 141-156.

[2] ANDRADE, A. M. Efeitos da fertilização mineral e da calagem na produção e na qualidade da madeira $e$ do carvão de eucalipto. Viçosa, 1993. $105 \mathrm{f}$. Tese (Doutorado) - Universidade Federal de Viçosa.

[3] BLANKNHORN, F. A. Porosity and pore size distribution of Blach Cherry carbonized in an inert atmosphere. Wood Science, Madison, v.11, n.1, p. 23-29, 1978 .
[4] BRITO, J. O.; BARRICHELO, L. E. G. Correlações entre características físicas e químicas da madeira e a produção de carvão vegetal: II - Densidade da madeira $x$ densidade do carvão. IPEF, Piracicaba, v.14, p. 9-20, 1977.

[5] BURGER, L. M.; RICHTER, H. G. Anatomia da madeira. São Paulo: Nobel, 1991. 154 p.

[6] GOMES, P. A.; OLIVEIRA, J. B. Teoria da carbonização da madeira. In: PENEDO, W. R. (Ed.) Uso da madeira para fins energéticos. Belo Horizonte: CETEC, 1982. p. 27-41.

[7] MEDEIROS, C. A.; RESENDE, M. E. A. Alcatrão vegetal: perspectivas de produção e utilização. Revista da Fundação João Pinheiro, Belo Horizonte, v.13, n.9-12, p. 42-48, 1983.

[8] MENDES, M. G.; GOMES, P. A.; OLIVEIRA, J. B. Propriedades e controle de qualidade do carvão vegetal. In: PENEDO, W. R. (Ed.) Produção e utilização do carvão vegetal. Belo Horizonte: CETEC, 1982. p. 75-89.

[9] OLIVEIRA, L. T.; ALMEIDA, M. R. Avaliação do carvão vegetal. In: PENEDO, W. R. (Ed.) Uso da madeira para fins energéticos. Belo Horizonte: CETEC, 1980. p. 43-53.

[10] LLIVEIRA, J. B.; VIVACQUA FILHO, A.; MENDES, M. G.; GOMES, P. A. Produção de carvão vegetal: aspectos técnicos. In: PENEDO, W. R. (Ed.) Produção e utilização de carvão vegetal. Belo Horizonte: CETEC, 1982. p. 59-73.

[11]OLIVEIRA, J. B.; GOMES, P. A.; ALMEIDA, M. R. Caracterização do processo de fabricação de carvão em fornos de alvenaria. In: PENEDO, W. R. (Ed.) Carvão vegetal: destilação, carvoejamento, propriedades, controle de qualidade. Belo Horizonte: CETEC, 1982. p. 63-102.

[12]SARKANEN, K. V.; LUDWIG, C. H. Lignins: occurrence, formation, structure and reation. New York: John Wiley \& Sons, 1971. $916 \mathrm{p}$.

[13]SILVA, D. A . Pirólise de turfa e análise de seu carvão. Piracicaba, 1988. $108 \mathrm{f}$. Tese (Doutorado) Escola Superior de Agricultura Luiz de Queiroz, Universidade de São Paulo.

[14]SILVA, D. A .; BRITO, J. O . Qualidade do carvão vegetal oriundo de madeiras amazônicas - Balbina. Acta Amazônica, Manaus, v.19(único), p. 525-530, 1989.

[15]STIMELY, G. L.; BLANKENHOR, P. R. Effects of species, specimen size, and heating rate on char yield and fuel proprieties. Wood and Fiber Science, Lawrence, v.17, n.4, p. 477-489, 1985. 
[16]TRUGILHO, P. F.; REGAZZI, A. J.; VITAL, B. R. GOMIDE, J. L. Aplicação de algumas técnicas multivariadas na avaliação da qualidade da madeira de Eucalyptus e seleção de genótipos superiores para a produção de carvão vegetal. Revista Árvore, Viçosa, v.21, n.1, p. 113-130, 1997.

[17]UHART, E. A floresta amazônica: fonte de energia. Belém: Superintendência de Desenvolvimento da Amazônia, 1976. 144 p.
[18]VALENTE, O. F.; ALMEIDA, J. M.; VITAL, B. R.; DELLA LUCIA, R. M. Efeito da temperatura de carbonização nos rendimentos e propriedades do carvão vegetal produzido. Revista Árvore, Viçosa, v.9, n.1, p. 28-39, 1985.

[19]WENZL, H. F. J. The chemical technology of wood. New York: Academic Press, 1970. 692 p.

Recebido para publicação em 29 NOV 1999 [SA 013/1999] Aceito para publicação em 21 JUN 2001 